\title{
HIV in South Africa - depression and CD4 count
}

M Y H Moosa, MMedPsych, FCPsych, MB ChB, MCFP, BSC

F Y Jeenah, MMedPsych, MB ChB

M Vorster, MB BCh, MMedPsych, PhMed (Forensic Psychiatry)

Department of Neurosciences, University of the Witwatersrand, Johannesburg

Objective. Published studies on the prevalence of depressive symptoms using rating scales and the relationship between depression and immune status offer inconsistent results. Depressive symptoms are common and impact on functioning, quality of life, and health status, highlighting the importance of diagnosis and treatment of patients with HIV infection. The aim of the study was to determine the occurrence of depression among HIV-positive patients using the Beck's Depression Inventory (BDI) and to determine a relationship, if any, between depressive symptoms and CD4 count.

Method. Forty-one patients aged 18 years or more were recruited from the HIV outpatient clinic. All the subjects completed the 21-item BDI and their CD4 counts were determined. Patients who had a score of 10 or more on the BDI were considered positive for a depressive disorder.

Results. More than half $(56 \%)$ of the study sample had a BDI of $\geq 10$ indicating significant symptoms of depression. There was no significant difference in the CD4 counts between the depressed and non-depressed groups (p > 0.05), and no correlation between CD4 counts and BDI scores in the total study sample $(r=0.27, p>0.05)$. The affective components of the $\mathrm{BDI}$ contributed significantly to the overall $\mathrm{BDI}$ score compared with the somatic component $(p<0.05)$.

Conclusion. The evidence from the study supports the BDI as a suitable measure for identifying those patients who meet the Diagnostic and Statistical Manual of Mental Disorders (DSM) criteria for minor or major depression. The HIV epidemic is the most serious health challenge in South Africa and it is imperative that HIV-infected patients who complain of fatigue or insomnia be screened routinely for major depression, followed by a structured interview to confirm the diagnosis.
Serious illnesses such as cancer, heart disease, stroke and HIV infection are often accompanied by depression. Although the estimates of the prevalence of depressive symptoms in people with HIV infection have varied widely in the literature, it would appear that they occur frequently, and that major depressive disorder may be the most common psychiatric disorder.' Depression may alter the course of HIV infection by impairing immune function, influencing behaviour and contributing to nonadherence to therapy. Screening, evaluating, and treating this disorder is crucial and should be pursued systematically. ${ }^{2}$

The diagnosis of a major depressive disorder in HIV-infected patients can be complicated. Both depression and HIV disease result in similar somatic or physical symptoms. Fatigue, lethargy, low libido, diminished appetite, and weight loss may be manifestations of either HIV-related illnesses or depressive disorder. In contrast, cognitive and affective symptoms such as feeling sad, lack of interest in formerly enjoyable activities, guilt, and irritability are usually components of mood alone.

In today's psychiatric clinical practice, rating scales have come to play an ever-increasing role both in determining specific symptoms and diagnosing individual condition. Descriptive reports of psychiatric morbidity among those with HIV infection, which relied primarily on self-report rating scales, described high rates of symptomatic depression. The Beck Depression Inventory $(\mathrm{BDI})^{3}$ is a 21 -item self-rating scale for depression. A score $\geq 10$ is indicative of the presence of significant depression. According to Svanborg and $\mathrm{Aberg}^{4}$ the BDI is the most often used self-rating instrument for depressive symptoms and when compared with a self-rating version of the Montgomery Asberg Depression Rating Scale (MADRS-S), was found to be equivalent. Similar findings were found by Kalichman et al. ${ }^{5}$ and Cockram et al. ${ }^{\circ}$ when comparing with other rating scales.

In a study to determine the association of depressive symptoms with HIV-related mortality and decline in CD4 lymphocyte counts, Ickovis et al.' concluded that depressive symptoms are associated with HIV disease progression. In contrast, Evans 
et al. ${ }^{8}$ report that while levels of self-reported depressive symptoms in HIV-infected patients were high, no relationship was found between CD4 count and depressive symptoms, whereas viral load was positively correlated with elevated depressive symptoms. Greater distress was not associated with greater immunosuppression or more advanced illness stage, either concurrently or over time. Other studies also support this conclusion. ${ }^{9-11}$

Published studies on the prevalence of depressive symptoms using rating scales and the relationship between depression and immune status offer inconsistent results. Depressive symptoms are common and impact on functioning, quality of life, and health status, highlighting the importance of diagnosis and treatment of patients with HIV infection.

\section{Objectives}

The aim of the study was to determine: (i) occurrence of depression among HIV-positive patients attending an outpatient treatment clinic, using the BDI; and (ii) the association, if any, between depressive symptoms and CD4 counts.

\section{Method}

Patients aged 18 years or more were recruited from the HIV outpatient clinic. All subjects gave written informed consent to participate in the study, which was approved by the Committee for Research On Human Subjects, University of the Witwatersrand. All the subjects completed the BDI self-rating scale and had their CD4 counts determined.

\section{Measures}

\section{Beck's Depression Inventory}

The $\mathrm{BDI}^{3}$ is a self-administered 21 -item self-report scale measuring the manifestations of depression, with high internal consistency. The content of the BDI was obtained by consensus from clinicians regarding symptoms of depressed patients and the items are consistent with 6 of the 9 Diagnostic and Statistical Manual of Mental Disorders (DSM-IM categories for the diagnosis of depression. It takes approximately 10 minutes to complete and clients require a 5th - 6th grade reading age to understand the questions adequately. Those completing the scale are required to read each group of statements and identify the 1 that best describes the way they have felt over the preceding week. Each item comprises 4 statements (rated 0 - 3) describing increasing severity of the abnormality concerned. The scores for the 21 questions are added to obtain a total.

Interpretation of the results is as follows: a score of 5 - 9 indicates normal ups and downs, 10 - 18 mild to moderate depression; 19 - 29 moderate to severe depression and 30 - 63 severe depression. ${ }^{12}$ Results below 4 suggest possible denial of depression or faking good, and are below usual scores for normal individuals. Results over 40 are significantly above the scores of even severely depressed persons, suggesting possible exaggeration of depression, possibly characteristic of histrionic or borderline personality disorders.

\section{CD4 T-lymphocytes}

The CD4 T-lymphocyte is the primary target for HIV infection because of the affinity of the virus for the CD4 surface marker. The CD4 T-lymphocyte co-ordinates a number of important immunological functions, and a loss of these functions results in progressive impairment of the immune response. Measures of CD4+ T-lymphocytes are used to guide clinical and therapeutic management of HIV-infected persons. The three CD4 T-lymphocyte categories are defined as follows: ${ }^{13}$

- Category $1: \geq 500$ cells $/ \mu 1$

- Category 2: 200 - 499 cells/ $\mu \mathrm{L}$

- Category 3: < 200 cells $/ \mu 1$

\section{Data analysis}

Results are expressed as percentages of the total. Comparisons were made by univariate analysis of variance (ANOVA) followed by the chi-squared test. The Wilcoxon rank sum test and the signed-rank test were used for non-parametric data where appropriate. Leverne's test was used to test for equality of variance. Pearson's correlation coefficient $(r)$ was computed between selected variables. All analyses were done using the Statistical package for Social Sciences 10.0 for Windows (SPSS Inc., Chicago, III.). A value of $p<0.05$ was considered significant.

\section{Results}

The study sample comprised of 41 patients. They were divided into two groups - those with a BDI score of $<10$ and those with a score of $\geq 10$ (Table I).

More than half ( $N=23,56 \%$ ) of the patients had a BDI of $\geq 10$, 
Table I. Demographic data of the study sample (\% (N))

\begin{tabular}{|c|c|c|c|}
\hline & & $N=18$ & $N=23$ \\
\hline Variables & $N=41$ & $\mathrm{BDI}<10$ & $\mathrm{BDI}>10$ \\
\hline \multicolumn{4}{|l|}{ Age (yrs) } \\
\hline $18-30$ & $44(18)$ & $44(8)$ & $43(10)$ \\
\hline $31-45$ & $46(19)$ & $50(9)$ & $43(10)$ \\
\hline$\geq 46$ & $10(4)$ & $6(1)$ & $14(3)$ \\
\hline \multicolumn{4}{|l|}{ Gender } \\
\hline Male & $29(12)$ & $39(7)$ & $22(5)$ \\
\hline Female & $71(29)$ & $61(11)$ & $78(18)$ \\
\hline \multicolumn{4}{|l|}{ Marital status } \\
\hline Single/divorced/separated & $85(35)$ & $89(16)$ & $83(19)$ \\
\hline Married & $15(6)$ & $11(2)$ & $17(4)$ \\
\hline \multicolumn{4}{|l|}{ Employment status } \\
\hline Employed & $51(21)$ & $61(11)$ & $43(10)$ \\
\hline Unemployed & $49(20)$ & $39(7)$ & $57(13)$ \\
\hline \multicolumn{4}{|l|}{ Highest level of education } \\
\hline$<$ Grade 9 & $31(13)$ & $33(6)$ & $30(7)$ \\
\hline$\geq$ Grade 9 & $69(28)$ & $67(12)$ & $70(16)$ \\
\hline \multicolumn{4}{|l|}{ CD4 count } \\
\hline$<200$ & $37(15)$ & $39(7)$ & $34(8)$ \\
\hline $201-499$ & $51(21)$ & $44(8)$ & $57(13)$ \\
\hline$>500$ & $12(5)$ & $17(3)$ & $9(2)$ \\
\hline
\end{tabular}

indicating that they had significant symptoms of depression, compared with $44 \%(N=18)$ who scored below 10. Twenty per cent of the sample $(N=8)$ scored below 4 on the BDI (these are below usual scores for normal individuals, suggesting a possible denial of depression or faking good). None of the patients in the sample scored over 40 (these scores are significantly above those of even severely depressed persons).

There was no significant difference in the CD4 counts between the depressed and non-depressed groups $(p=0.22)$.

The majority of the patients were unmarried women, under 46 years of age with a grade 9 or higher level of education. However there was no significant difference with regard to age, gender, marital status, employment status and highest level of education between the depressed and non-depressed groups $(p>0.05)$

There was no correlation between the BDI scores and CD4 counts of the total study sample $(r=0.274, p>0.05)$ (Fig. 1).

The BDI looks at symptoms such as fatiguability, loss of appetite, weight loss, sleep disturbance and low energy level. These somatic symptoms may be attributable to HIV infection and to the progress of the disease and may confound the diagnosis. The depressed patients' scores were further broken down to determine the contribution of this somatic component to their total scores (Table II)

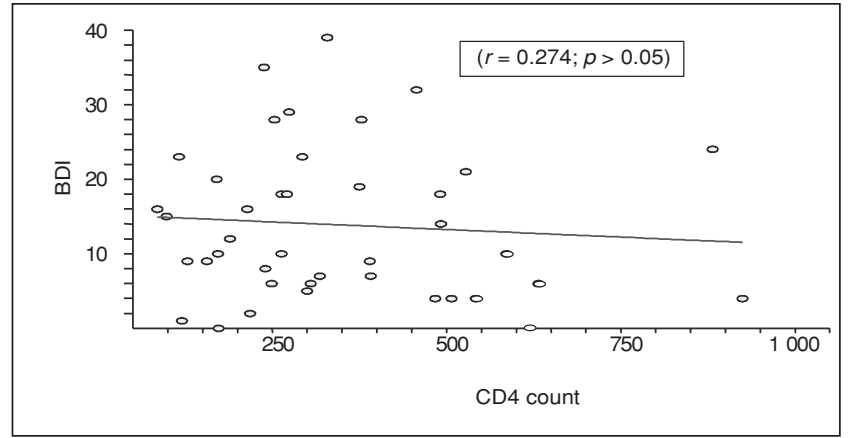

Fig. 1. Correlation between CD4 counts and BDI scores in the study sample.

The majority of patients scored highly on the affective component compared with these five somatic components ( $p>0.05)$ (Fig. 2).

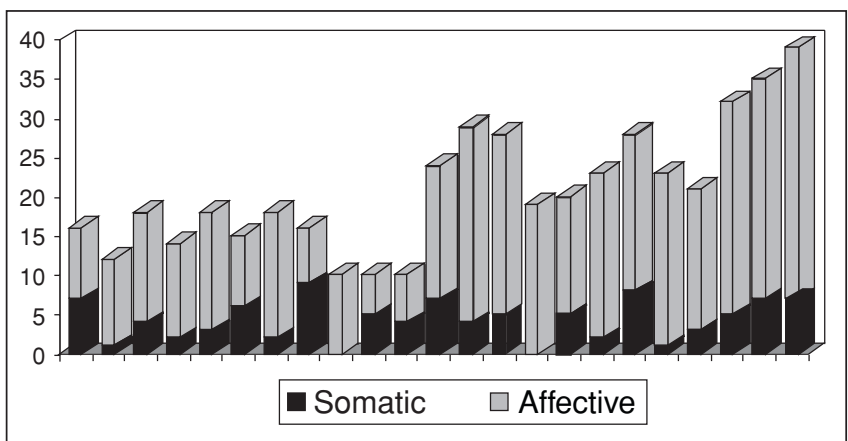

Fig. 2. Distribution of BDI scores (somatic and affective component) in the depressed subgroup of patients. 
Table II. Distribution of CD4 counts versus BDI scores (somatic component) in the depressed subgroup

\begin{tabular}{|c|c|c|c|c|c|c|c|c|}
\hline \multirow[b]{2}{*}{ CD4 count } & \multicolumn{2}{|c|}{$\begin{array}{c}\text { BDI } 10-18 \\
(N=11)\end{array}$} & \multirow[b]{2}{*}{ CD4 count } & \multicolumn{2}{|c|}{$\begin{array}{c}\text { BDI } 19-29 \\
(N=9)\end{array}$} & \multirow[b]{2}{*}{ CD4 count } & \multicolumn{2}{|c|}{$\begin{array}{c}\text { BDI } 30-63 \\
(N=3)\end{array}$} \\
\hline & Total & Somatic & & Total & Somatic & & Total & Somatic \\
\hline 35 & 16 & 7 & 832 & 24 & 7 & 407 & 32 & 5 \\
\hline 139 & 12 & 1 & 224 & 29 & 4 & 188 & 35 & 7 \\
\hline 213 & 18 & 4 & 203 & 28 & 5 & 279 & 39 & 7 \\
\hline 442 & 14 & 2 & 325 & 19 & 0 & & & \\
\hline 441 & 18 & 3 & 120 & 20 & 5 & & & \\
\hline 48 & 15 & 6 & 66 & 23 & 2 & & & \\
\hline 221 & 18 & 2 & 328 & 28 & 8 & & & \\
\hline 164 & 16 & 9 & 243 & 23 & 1 & & & \\
\hline 213 & 10 & 0 & 478 & 21 & 3 & & & \\
\hline 133 & 10 & 5 & & & & & & \\
\hline 536 & 10 & 4 & & & & & & \\
\hline
\end{tabular}

\section{Discussion}

The findings of this study indicate that depressive symptoms are common among patients with HIV infection, with over half of the study sample having a $\mathrm{BDI}$ of $\geq 10$. The majority of the depressed patients scored higher on the affective component of the BDI (such as sadness, pessimism, indecisiveness, sense of failure, dislike of self and episodes of cryingl, suggesting that the high scores in these patients are more likely to be related to the psychological disturbances of major depression. However there was no correlation between CD4 counts and BDI scores. The patients were recruited from the HIV clinic at Johannesburg hospital. The latter's main referral source is the hospital's antenatal clinic, which might account for the fact that most of the patients were women under 46 years of age. The majority of the patients had a grade 9 or higher level of education, meeting the criteria that clients require a 5th - 6th grade reading age to understand the questions of the BDI adequately. Certain limitations of the study warrant consideration. The relatively small sample size hampered statistical comparisons between treatment groups. The sample was a small group of patients attending the HIV clinic at the hospital and may not be representative of the population in general. Nutritional status and any other co-morbid medical disorders were not considered in this study. However these limitations probably do not detract from the final conclusions.

\section{Conclusion}

Although our study leaves unanswered certain questions concerning screening for depression in patients with HIV, we can conclude that the evidence supports the reliability of the BDI as a screening tool. The HIV epidemic is the most serious health challenge in South Africa and it is imperative that HIV-infected patients who complain of fatigue or insomnia be screened routinely for major depression, followed by a structured interview to confirm the diagnosis and to treat the depression.

\section{References}

1. Judd FK, Mijch AM. Depressive symptoms in patients with HIV infection. Aust NZJ Psychiatry 1996; 30: 104-109

2. Lyketsos CG, Hanson A, Fishman M, et al. Screening for psychiatric morbidity in a medical outpatient clinic for HIV infection: the need for a psychiatric presence. Int J Psychiatry Med 1994; 24: 103-1 13

3. Beck AT, Ward CH, Mendelson M, Mock J, Erbaugh J. An inventory for measuring depression. Arch Gen Psychiatry 1961; 4: 53-63.

4. Svanborg P, Asberg M. A comparison between the Beck Depression Inventory (BDI) and the self-rating version of the Montgomery Asberg Depression Rating Scale (MADRS). J Affect Disord 200 1; 64: 203-216

5. Kalichman SC, Sikkema KJ, Somlai A. Assessing persons with human immunodeficiency virus (HIV) infection using the Beck Depression Inventory: disease processes and other potential confounds. J Pers Assess 1995; 64: 86-100.

6. Cockram A, Judd FK, Mijch A, Norman T. The evaluation of depression in inpatients with HIV disease. CNS Spectr 2003; 8: 52-58.

7. Ickovics JR, Hamburger ME, Vlahov D, et al. HIV Epidemiology Research Study Group. Mortality, CD4 cell count decline, and depressive symptoms among HIVseropositive women: longitudinal analysis from the HIV Epidemiology Research Study. JAMA 2001; 285: 1466-1474.

8. Evans, DL, Ten Have TR, Douglas SD, et al. Association of depression with viral load, CD8 T lymphocytes and natural killer cells in women with HIV infection. Am J Psychiatry 2002; 159:: 1752-1759.

9. Rabkin JG, Williams JBW, Remien RH, et al. Depression, distress, lymphocyte subsets and HIV symptoms on two occasions in HIV-positive homosexual men. Arch Gen Psychiatry 1991; 48:111-119.

10. Kessler RC, Foster C, Joseph J, et al. Stressful life events and symptom onset in HIV infection. Am J Psychiatry 1991;148: 733-738.

11. Evans DL, Ten Have TR, Douglas SD, et al. Association of depression with viral load, CD8 T lymphocytes, and natural killer cells in women with HIV infection. Am J Psychiatry 2002; 159: 1752-1759.

12. Groth-Marnat G. The Handbook of Psychological Assessment 2nd ed. New York: John Wiley and Sons, 1990

13. Centers for Disease Control. 1993 revised classification system for HIV infection and expanded surveillance case definition for AIDS among adolescents and adults. Morb Mortal Wkly Rep 1992; 41: 1-19. 